\title{
Science, Worldviews, and Education
}

\author{
HUGH G. GAUCH JR.
}

Crop and Soil Sciences, Cornell University, 519 Bradfield Hall, Ithaca, NY, 14853-1901, USA

E-mail:.hgg1@cornell.edu

\begin{abstract}
Whether science can reach conclusions with substantial worldview import, such as whether supernatural beings exist or the universe is purposeful, is a significant but unsettled aspect of science. For instance, various scientists, philosophers, and educators have explored the implications of science for a theistic worldview, with opinions spanning the spectrum from positive to neutral to negative. To delineate a mainstream perspective on science, seven key characterizations or "pillars" of science are adopted from position papers from the world's largest scientific organization, the American Association for the Advancement of Science. Based on those pillars and an examination of scientific method, I argue that the presuppositions and reasoning of science can and should be worldview independent, but empirical and public evidence from the sciences and humanities can support conclusions that are worldview distinctive. I also critique several problematic perspectives: asserting that science can say nothing about worldviews and the opposite extreme of insisting that science decisively supports one particular worldview; weakening science so severely that it lacks truth claims; and burdening science with unnecessary presuppositions. Worldview-distinctive conclusions based on empirical evidence are suitable for individual convictions and public discussions, but not for institutional endorsements and scientific literacy requirements.
\end{abstract}

Key words: American Association for the Advancement of Science (AAAS), atheism, empirical evidence, humanities, human nature, miracles, natural theology, powers and limits of science, presuppositions, public evidence, realism, religion, scientific literacy, scientific method, scientism, skepticism, standard logic, testability, theism, worldview

\section{Introduction}

Can science reach farther than its ordinary investigations of galaxies, flowers, bacteria, electrons, and such? Can science also tackle life's big questions, such as whether God exists and whether the universe is purposeful?

Life's grand questions could be termed religious or philosophical or worldview questions. But a single principal term is convenient here and my

I appreciate helpful comments on earlier versions of this paper from William Cobern, Simon Conway Morris, Peter Davson-Galle, Gurol Irzik, Michael Matthews, Robert Nola, Roger Trigg, and three anonymous reviewers. 
preference is the rather broad term, worldview (or Weltanschaunng). "A worldview constitutes an overall perspective on life that sums up what we know about the world, how we evaluate it emotionally, and how we respond to it volitionally" (Rudolf A. Makkreel, in Audi 1999, p. 236; likewise, Craig 1998, vol. 3, pp. 77-83). This paper assesses science's competence as its ambitions expand from ordinary to worldview questions.

Science's relationship with various worldviews, both theistic and atheistic, is one of the most significant and yet unsettled aspects of science. Indeed, this controversy is a perennial topic for journals in science, philosophy, and education. This paper has two distinctive features.

First, science's worldview import is approached as a four-way conversation. The four parties considered here are (1) prominent scientists, (2) philosophers of science, (3) science educators, and (4) position papers on science education from leading scientific organizations, particularly the American Association for the Advancement of Science (AAAS) and the National Academy of Sciences (NAS, including its National Research Council, NRC) of the United States. Second, science's powers and limits and particularly the extent of science's potential for reaching conclusions having substantial worldview import - are seen here principally as a direct implication of science's method. Hence, a penetrating understanding of scientific method is the gateway to a clear and balanced perspective on science and worldviews.

This paper reviews the broad spectrum of opinions on science's worldview import expressed by scientists, philosophers, educators, and position papers on science education. Then merely stipulatory aspects of these diverse opinions are distinguished from truly substantive aspects. The principal resource for evaluating these opinions is to affirm seven key statements or "pillars" from AAAS position papers that support a mainstream and beneficial perspective on science. Drawing on those pillars, I defend three theses regarding scientific method and worldview import. Then these theses are deployed to show that worldview beliefs can be testable, to critique three extremely common and yet highly problematic perspectives, and to distinguish necessary from unnecessary presuppositions of science. Finally, brief conclusions commend a perspective on science's worldview import that aligns with mainstream science as delineated by position papers from the AAAS and other leading scientific organizations.

\section{A Spectrum of Opinions}

Scientists hold diverse views on science and God, as documented by extensive surveys (Easterbrook 1997; Larson and Witham 1999). For example, Scientific American reported an exchange between Richard Dawkins, 
identified as a biologist and "an agnostic leaning toward atheism," and Simon Conway Morris, an evolutionary paleontologist and a Christian (Horgan 2005). Dawkins thought that neither the fine-tuning of the universe nor the origin of life requires an explanation involving God. But Conway Morris 'retorted that he found Dawkins's atheism 'archaic' and asserted that the resurrection and other miracles attributed to Christ were 'historically verifiable'." He believes that it is imperative to develop a theology of evolution (Conway Morris 2003). Also contested are the cause and legitimacy of religious belief and experience. In purely naturalistic and quite derogatory terms, Dawkins (2003) explains away religions as "cognitive viruses" or "memes" that spread among humans, even though religions are irrational and harmful (also see Bering 2006). On the other side, Francis Collins, the director of the Human Genome Project, argues that evolution and theism are compatible and that naturalistic explanations of religion and morality are wanting (Collins 2006).

Philosophers have also expressed quite diverse opinions about science's worldview import, particularly whether science supports theism, atheism, or neither. For the sake of brevity, just one philosophy journal is considered here, namely the British Journal for the Philosophy of Science. That journal has carried an extended exchange about the cosmological argument. Swinburne $(2000,2005)$ argued that the universe provides evidence for God's existence, whereas Grünbaum (2000, 2004, 2005) dismissed this argument. Craig (1992), O’Hear (1993), Callender (2004), Weisberg (2005), and Monton (2006) also discuss the cosmological argument. For another example, in response to David Hume's legacy, Holder (1998) and Shogenji (2003) examined the conditions under which reported miracles, especially with multiple witnesses, may provide support for the existence of God. For a third example, Sterelny (2006) discussed Richard Dawkins's naturalistic explanation of religions (also see Dennett 2006).

Science educators also hold diverse views and encounter intense controversies. Again for the sake of brevity, just one education journal is sampled here, namely this journal, Science \& Education. The following representative papers concern science's interaction with religions or worldviews. Hansson and Redfors (2006a, b) surveyed high-school students' opinions, which turned out to be quite diverse, regarding whether science (especially physics) is compatible with belief in God and in miracles, asking them to express both their own view and the view that they take to be prevalent among scientists. They also examined the students' understandings of the presuppositions of science, particularly to discern whether these presuppositions imply a scientism that excludes religion. Cobern (2000) discussed students' integration of science and religion and also provided a historical perspective. Gauld (2005) explored habits of mind for science 
and religion in both students and teachers. He argued for there being less conflict than some other educators suppose, particularly since both science and religion can embody a respect for evidence. Keranto (2001) investigated the perceived credibilities of scientific and religious claims among future science teachers. Nola (2003) showed that the perennial debate in philosophy between realist and anti-realist epistemologies infects education with this same turmoil. Obviously, anything that will unsettle ordinary scientific knowledge will also more than unsettle ambitious worldview claims. Smith et al. (1995), Pennock (2002), and Hofmann and Weber (2003) discussed diverse views on the teaching of evolution and creationism as regards public policy, legal arguments, scientific facts, philosophical merits, and educational goals. Davson-Galle (2006) expressed ethical concerns about compulsory science education incorporating controversial philosophical or worldview content. On the other hand, Irzik and Irzik (2002) acknowledged the controversies and tensions inherent in a pluralistic or multicultural society, and yet argued that the ideal of a good life favors a vigorous science offering public, universal knowledge claims when the evidence is clear - with no capitulation to ethnic or cultural prejudices. An additional dozen papers from this journal are encountered later in this article.

Having sampled personal opinions from individual scientists, philosophers, and educators regarding science's worldview import, next consider position papers on science education from leading scientific organizations. The relationship between science and worldviews is a prominent concern in these papers.

The powers and limits of science are consistently identified by position papers as an essential component of scientific literacy. For instance, "Being liberally educated requires an awareness not only of the powers of scientific knowledge but also of its limitations," so learning science's limits "should be a goal in all science courses" (AAAS 1990, pp. 20-21). Likewise, science and technology undergraduates should be able to answer several specific questions, including these three: "How are the approaches that scientists employ to view and understand the universe similar to, and different from, the approaches taken by scholars in other disciplines outside of the natural sciences? What kinds of questions can be answered by the scientific and engineering methods, and what kinds of questions lie outside of these realms of knowledge? How does one distinguish between science and pseudoscience?" (NRC 1999, p. 34).

A particularly important aspect of this boundary between science's powers and limits regards whether scientific inquiry can address worldview questions. The AAAS says that there are "beliefs that - by their very nature - cannot be proved or disproved (such as the existence of supernatural 
powers and beings, or the true purposes of life)" (AAAS 1989, p. 26). So, science is neutral as regards both theism and atheism.

However, in another position paper, the AAAS claims that science supports a particular worldview, that "There can be no understanding of science without understanding change and the fact that we live in a directional, although not teleological, universe" (AAAS 1990, p. xiii; also see p. 24). Now "not teleological" just means purposeless. Since it is common knowledge that the world's great monotheisms - Judaism, Christianity, and Islam - view the world and life as purposeful, this pronouncement of a purposeless universe is tantamount to an endorsement of atheism.

Awkwardly, one AAAS position paper says that science cannot examine the purposes of life, whereas another declares emphatically that science reveals a purposeless universe. Clearly, these two statements are flatly contradictory.

How can this contradiction be resolved? And more generally, among all of the above individual opinions and institutional positions, what contributes to a legitimate perspective on science's worldview import?

Science educators have discerned that the principal resource for properly determining the boundary between science's powers and limits is an adequate understanding of scientific method. "Understanding how science operates is imperative for evaluating the strengths and limitations of science" (William F. McComas, in McComas 1998, p. 12; also see Gruender 2001). Similarly, "The ability to distinguish good science from parodies and pseudoscience depends on a grasp of the nature of science" (Matthews 2000, p. 326; also see Keeports and Morier 1994 and Machamer 1998). Furthermore, this topic of science's method and limits connects with some broader issues. "Students educated in science should have an appreciation of scientific methods, their diversity and their limitations. They should have a feeling for methodological issues, such as how scientific theories are evaluated and how competing theories are appraised, and a sense of the interrelated role of experiment, mathematics and religious and philosophical commitment in the development of science" (Matthews 1994, pp. 2-3).

Accordingly, this paper's principal undertaking is its analysis of scientific method in Section 5, involving the defense of three theses. Clarity about scientific method leads to clarity about science's potential to address worldview questions. However, before that, two brief sections discuss some crucial preliminaries.

\section{Stipulatory and Substantive Issues}

Can science support theism or atheism or neither? Among all of the issues regarding science's worldview import that were reviewed in the previous 
section, this is the most significant and contentious dispute. And obviously, this dispute over science's bearing on the worldview question about whether God exists is closely related to additional questions of immense scholarly and popular interest, including whether the universe is purposeful and whether miracles occur (see Hansson and Redfors 2006a).

This big question - about science's support for theism or atheism or neither - is a vexed question because it involves a tangled mixture of three stipulatory issues and one substantive issue. Until these four issues have been distinguished, there is little hope of a useful analysis, or even of a clear understanding of what many of the above quotations and ideas really amount to.

A stipulatory issue, involving social conventions more so than philosophical reasons, regards the domain of science. Are supernatural beings and events, including God and miracles, inside or outside science's domain? The rather prevalent doctrine of methodological naturalism says that scientific explanations should involve only natural entities, not anything supernatural, such as God or angels. But this doctrine, even if adopted wholeheartedly by a given individual or institution, is about the ordinary workings or legitimate business of science, whereas it is silent about whether supernatural beings exist and whether they interact with physical things in observable ways. (A different doctrine, ontological naturalism, says that only the physical world exists and nothing supernatural.)

Another stipulatory issue is the boundary between science and the humanities, particularly philosophy, theology, and history. Given the topic of, say, reported miracles in the Bible or elsewhere, regardless whether a given person believes or disbelieves any of these reports, various persons may feel differently about whether this topic is the proper business of science or theology or history or whatever, or perhaps several of these disciplines. For better or for worse, science's domain shifts from century to century, from nation to nation, and from culture to culture. Inevitably, science's boundary is somewhat fuzzy and controversial.

A third and final stipulatory issue is that scientific method may be given a much larger domain than science itself. Hence, science's method may receive a different verdict than science's hypotheses and evidence. That scientific method has broad applicability is the official position of the AAAS. "There are ... certain features of science that give it a distinctive character as a mode of inquiry. Although those features are especially characteristic of the work of professional scientists, anyone can exercise them in thinking scientifically about many matters of interest in everyday life" (AAAS 1989, p. 26). "All sciences share certain aspects of understanding - common perspectives that transcend disciplinary boundaries. Indeed, many of these fundamental values and aspects are also the province of the humanities, 
the fine and practical arts, and the social sciences" (AAAS 1990, p. xii; likewise, pp. 11, 16).

However, despite the stipulatory issues that give science a fuzzy boundary in other respects, it is abundantly clear that science's worldview import is a legitimate topic for science. As the world's largest scientific organization, being the umbrella organization for nearly 300 scientific societies, the AAAS bids fair as representing a mainstream perspective on science. AAAS position papers on science address religion, God, the Bible, the clergy, prayer, and miracles with mostly sensible and balanced perspectives. Also, one can look forward to the ongoing conferences and publications of the Dialogue on Science, Ethics, and Religion (DoSER) program of the AAAS. One notable publication is a study of the interactions between science and Christianity (Lindberg and Numbers 2003).

Furthermore, it is manifestly clear that science's interaction with various worldviews, theistic and atheistic, is of sustained interest to many individual scientists. Indeed, considering only four of the main general science journals - Science (published by the AAAS), Nature, Scientific American, and American Scientist - hardly a month goes by without at least one commentary or book review, or even a feature article, regarding science and worldviews. That the scientific community is interested in larger questions than which brand of light bulbs last longest attests to its vitality, courage, and curiosity.

Lastly, besides the above three stipulatory issues, there is also one huge substantive issue regarding worldviews. Is it possible for the sciences and humanities to find empirical and public evidence that bears on worldview hypotheses (such as theism and atheism), thereby providing reasons that count across worldviews in favor of a specific worldview?

Focusing on "empirical and public evidence" in this question engages all worldviews alike. And combining "the sciences and humanities" bypasses stipulatory issues about the boundaries between the sciences and various humanities. Hence, this substantive question concerns what can be known about reality by means of publicly accessible evidence, irrespective of diverse views on controversial but inconsequential stipulatory issues. Having mentioned stipulatory issues in this section, the remainder of this paper concerns the substantive issue of science's worldview import.

\section{Seven Pillars of Science}

Many great ideas that have been pillars of scientific thinking and orthodoxy for centuries are emphasized in the AAAS vision of the nature and practice of science. Seven especially simple and important ones, which suffice for present purposes, are listed and named here. Before progressing to 
more advanced and controversial matters, these basics merit review and affirmation.

Pillar P1: Realism. The physical world, which science seeks to understand, is real. This pillar is expressed beautifully in the simple words that "science is the art of interrogating nature" with "Commitment to understanding the natural world" (AAAS 1990, p. 17).

Pillar P2: Presuppositions. Science presupposes that the world is orderly and comprehensible. "Science presumes that the things and events in the universe occur in consistent patterns that are comprehensible through careful, systematic study" (AAAS 1989, p. 25; likewise, 1990, p. 16).

Pillar P3: Evidence. Science demands evidence for its conclusions. "Sooner or later, the validity of scientific claims is settled by referring to observations of phenomena. ... When faced with a claim that something is true, scientists respond by asking what evidence supports it" (AAAS 1989, pp. 26, 28).

Pillar P4: Logic. Scientific thinking uses standard and settled logic. Scientists "tend to agree about the principles of logical reasoning that connect evidence and assumptions with conclusions" (AAAS 1989, p. 27; likewise, 1990, p. 16).

Pillar P5: Limits. Science has limits in its understanding of the world. "There are many matters that cannot usefully be examined in a scientific way" (AAAS 1989, p. 26).

Pillar P6: Universality. Science is public, welcoming persons from all cultures. "Men and women of all ethnic and national backgrounds participate in science and its applications. ... Because of the social nature of science, the dissemination of scientific information is crucial to its progress" (AAAS 1989, pp. 28-29).

Pillar P7: Worldview. One of science's important ambitions is contributing to a meaningful worldview. "Science is one of the liberal arts ... unquestionably," and "the ultimate goal of liberal education" is the "lifelong quest for knowledge of self and nature," including the quest "to seek meaning in life" and to achieve a "unity of knowledge" (AAAS 1990, pp. xi, 12, 21; likewise, 1989, p. 134).

These seven ideas might seem merely platitudinous. But they are actually quite powerful when their implications are worked out. They are like Kolmogorov's three simple probability axioms that generate countless probability theorems, or Maxwell's four little equations that imply all of classical electricity and magnetism.

The great fruitfulness of these ideas emerges from their joint assertion, rather than their individual contents. For instance, the presupposition of a comprehensible world ( $P 2$ ) energizes a hopeful pursuit of realism (P1), and that realism is implemented by science demanding adequate evidence (P3) and using standard logic (P4). 
Controversial and even contradictory claims emerge occasionally as AAAS position papers progress to advanced and challenging topics, including the present topic of science's worldview import. Then the seven pillars serve a vital role. The merit of a questionable claim can be judged by its coherence, or lack thereof, with the seven pillars.

\section{Scientific Method}

This section develops three theses intended to clarify science's relationship with worldviews, with due consideration of the seven pillars of scientific orthodoxy. They concern full disclosure of scientific reasoning, legitimate presuppositions for science, and science's worldview import. I have explored these and related topics in greater detail in my text on scientific method (Gauch 2002). However, the following brief account suffices for present purposes. Incidentally, reviews of this book have appeared in this and another education journal (Matthews 2004; Sherburn 2004).

\subsection{FULL DISCLOSURE}

Thesis 1 The first necessity for reaching a clear verdict on science's worldview import is full disclosure of scientific reasoning, exhibiting all of the premises required to support a conclusion. Every scientific conclusion requires premises of three kinds: presuppositions, evidence, and logic.

Full disclosure is the first prerequisite in showing that a particular question is within science's reach (P5) and that a particular conclusion is true (P1). Only with everything out on the table can every component of an argument be checked. By contrast, a telling sign of "shoddy" and "doubtful assertions and arguments" is that "The premises of the argument are not made explicit" (AAAS 1989, p. 139). Incidentally, depending on the strength of the evidence in a given case, the conclusion may be certain or probable.

Full disclosure is especially important for ambitious scientific inquiries addressing worldview issues, such as whether life is purposeful. But the requirements for full disclosure are best learned by beginning with a simple example, which suffices to reveal the general structure of scientific thinking, regardless how complex.

Imagine or perform the following experiment. Envision or obtain a coin and an opaque cup covered with an opaque lid. Have someone else flip the coin, without your observing this process, and then put the coin in the cup if heads, or else put the coin elsewhere if tails. The question is then, "Is there a coin in the cup?" with the competing hypotheses being "There is a coin in the cup" and "There is not a coin in the cup." And the experimental observation will be to lift the lid and look inside the cup. 
The present endeavor is to give a complete, fully disclosed argument with the conclusion that there is or is not a coin in the cup, as the case may be. This means that all premises needed to reach the conclusion must be stated explicitly, with nothing lacking.

Assume that the experiment's outcome is seeing a coin in the cup. Symbolize seeing the coin in the cup by " $S$ " and its existence by "E," where the hypotheses are E and not-E. This experimental evidence supplies the premise, "S." The presupposition that the world is comprehensible supplies the premise that, in ordinary circumstances, seeing implies existence, or "S implies E." Finally, logic supplies the premise that a valid argument form (modus ponens) draws the experiment's conclusion: S; S implies E; therefore E. This reasoning is fully disclosed, these three premises supporting the first hypothesis that "There is a coin in the cup."

The general point is that the justification of a scientific conclusion amounts to legitimization of the presuppositions, evidence, and logic needed to support that conclusion. This is the crux of scientific method. Incidentally, all of these kinds of premises were identified already by pillars $P 2-P 4$, though the theory connecting them was not presented until this section.

The concept of evidence is somewhat subtle, being deeply interconnected with presuppositions and hypotheses. Evidence has a dual nature, being admissible and relevant. Evidence is admissible, relative to available presuppositions, if those presuppositions make it accessible. For instance, presuppositions about the comprehensibility of the physical world allow for empirical evidence, such as citing the seeing of a coin. Otherwise, pillar P3 would be utterly undone. And evidence is relevant, relative to a particular set of hypotheses, if different hypotheses expect different observations, so that the actual observation bears differentially on the hypotheses' credibilities. For instance, seeing a coin in the cup confirms the hypothesis that there is a coin in the cup, whereas it disconfirms the alternative hypothesis. Data are just admissible observations, whereas evidence is data plus interpretations of the data showing clear relevance for evaluating a specific hypothesis set (AAAS 1989, pp. 26-30, 1990, pp. 16-18).

Presuppositions and evidence are different, though complementary. Presuppositions answer the question: How can we reach any conclusion at all to the present inquiry? They do not bear differentially on the credibilities of the hypotheses. But evidence answers the question: How can we assert one particular conclusion rather than another? For instance, presuppositions about the comprehensibility of the world are needed to reach any conclusion about a coin in a cup, whereas the evidence of seeing a coin in the cup supports assertion of the specific hypothesis that there is a coin in the cup.

Testability is a core value of science. "To be useful, a hypothesis should suggest what evidence would support it and what evidence would refute it" 
(AAAS 1989, p. 27). The present simple example involving a coin exemplifies testable hypotheses. Different predictions regarding a physical outcome that is publicly accessible offer scientists an opportunity to test hypotheses or theories. Although hypothesis tests feature accuracy in fitting the data, additional more subtle criteria are also in play. Another consideration is parsimony or simplicity, which favors simpler theories among those that fit the data equally well (Gauch 2002, pp. 269-326). Yet another consideration is unification (Schupbach 2005). That is, "The credibility of scientific theories often comes from their ability to show relationships among phenomena that previously seemed unrelated" (AAAS 1989, p. 27). There are still more criteria for hypothesis testing and there are also interactions among these criteria. For instance, there is an interaction between parsimony and accuracy that has huge theoretical and practical significance (Gauch 2006). Anyway, the essential point here is that science concerns testable matters.

It is important to have identified the basic components of scientific reasoning - hypotheses, presuppositions, evidence, logic, and conclusions because statements with these different logical roles interact with worldviews in different ways. A statement's logical role is as important as its content.

The difference between "The universe is purposeless" and "The universe is purposeful" is obvious, marking out a vigorous debate. But equally different are "The universe is purposeless" in the logical role of a presupposition and this same "The universe is purposeless" in the role of a conclusion. As a presupposition, its function would be limited to self-congratulatory discourse among kindred spirits. But as a conclusion from a sound argument, its audience would be the larger world. Of course, if a statement appears in an argument as both a presupposition and a conclusion, then the diagnosis is circular reasoning. Likewise, if a key statement's logical role is unspecified and unclear, then the diagnosis is amateurish discourse.

\subsection{LEGITIMATE PRESUPPOSITIONS}

Thesis 2 Science's presuppositions about the existence and comprehensibility of the physical world are best legitimated by an appeal to rudimentary common sense. Anything less leaves science vulnerable to radical skepticism, which questions the comprehensibility or even the existence of the physical world. Anything more substantive, coming from a particular and favored worldview (such as atheism, Buddhism, Christianity, or Islam), needlessly jeopardizes science's status as a public enterprise.

Necessarily and inescapably, the belief that "The physical world exists and is substantially comprehensible to us" is a presupposition of science, not a conclusion. Neither can science inherit such a belief from some other discipline that can prove or support it. Instead, philosophy can prove that 
no supporting evidence is possible. Some beliefs are basic and oblivious to evidence because nothing else is more certain. For instance, "my not having been on the moon is as sure a thing for me as any grounds I could give for it" (Ludwig Wittgenstein, in Anscombe and Wright 1969, p. 17e).

So, presuppositions must be an exception to the ordinary pattern that beliefs are justified by presenting evidence. Instead, the legitimization of science's presuppositions must involve some different strategy.

One simple strategy runs as follows. Adopt by faith a little scrap of rudimentary common sense, such as "I have not been on the moon" or "Moving cars are hazardous to pedestrians." Then analyze this statement to understand what has already been presupposed about ourselves and our world, which will include that the physical world exists and is substantially comprehensible. Note that the same presuppositions would emerge from reflection on any such scrap of common sense and that these presuppositions are both necessary and sufficient to give science an ordinary realist interpretation (Polanyi 1962, pp. 160-171; Nash 1963, pp. 3-62).

This strategy gives science just the right forum. On the one hand, cheerful confidence in some trinket of trivial knowledge excludes radical skepticism from science's worldview forum, as pillar $P l$ requires. Science's business is to presuppose common sense and then build scientific method, not to refute the skeptic and thereby establish common sense. On the other hand, all other worldviews are welcomed. Cobern and Loving (2001) and Meera Nanda (in Koertge 1998, pp. 286-311) discuss the functionality of standard science in our multicultural world.

Fortunately, rather few persons would deny, with sincerity or consistency, that "Moving cars are hazardous to pedestrians." As Palmer (1985, p. 14) quips, "Skeptics are like dragons. You never actually meet one, but keep on running across heroes who have just fought with them, and won." Consequently, a single formulation of science's presuppositions can work equally well for nearly everyone, in keeping with the requirement of pillar P6 that science be public.

The simple presuppositions in pillar $P 2$ do modest work, merely insisting that the physical world is comprehensible to us. They do not address the larger issue of how our world and we came to be so constituted, which requires the larger resources of a worldview. Different worldviews give divergent accounts. But fortunately, analysis of rudimentary common sense, which involves worldview commonalities, supplies the needed presuppositions.

Nevertheless, philosophical questions can be raised regarding whether a given worldview can provide a coherent and satisfactory explanation for the existence and adequacy of the human rationality that common sense and mainstream science must presume. Certainly, "science has itself to 
appeal to a metaphysical basis," that is, to an account of "the nature of reality" (Trigg 1993, pp. 4, 14). However, a separate issue remains regarding whether a deep account of reality is to be mandated as a requirement for scientific literacy or is to be left as an optional interest of some scientists. The latter seems more sensible and realistic.

On pain of circular reasoning, it is a principle of logic that whatever is presupposed cannot also be concluded. The reverse also holds, that beliefs that are not presupposed retain their eligibility to be hypotheses with potential to become conclusions if supported by appropriate evidence. For instance, because science does not presuppose that electrons do or else do not exist, science can reach a conclusion about this, given proper evidence. Therefore, this recommended installation of science's presuppositions serves pillar $P 7$, giving science an exciting reach before encountering its limits. Science's power to investigate so much emerges from its presupposing so little.

\subsection{WORLDVIEW IMPORT}

Thesis 3 Science is worldview independent as regards its presuppositions and methods, but scientific evidence, or empirical evidence in general, can have worldview import. Methodological considerations reveal this possibility and historical review demonstrates its actuality.

Pillar $P 7$ affirms that science contributes to a meaningful worldview. This power of science follows easily from methodological considerations involving two of the other pillars of science. Pillar $P 2$ grants science basic, common-sense presuppositions, which deliberately include no worldviewdistinctive beliefs. And pillar P4 adopts standard logic, including the principle that beliefs that are not presupposed retain their eligibility to be hypotheses with potential to become conclusions if supported by appropriate evidence. Therefore, worldview-distinctive beliefs can retain eligibility.

It may seem paradoxical or surprising that a worldview-independent method could yield worldview-distinctive conclusions. But of course, only a method that did not presuppose or favor a particular outcome could yield a conclusion worthy of consideration. A worldview-independent method applied to worldview-informative evidence can reach worldview-distinctive conclusions. The action is in the evidence. The evidence reflects reality.

Furthermore, the AAAS asserts repeatedly that science having worldview import is not merely a possibility as methodological considerations indicate, but an actuality as historical review confirms. "The knowledge" that science "generates sometimes forces us to change - even discard - beliefs we have long held about ourselves and our significance in the grand scheme of things," that is, worldview beliefs (AAAS 1989, p. 134). "Scien- 
tific ideas ... influence - and are influenced by - the wider world of ideas" (AAAS 1990, p. 24). The AAAS cites numerous examples of scientific knowledge that historically have greatly influenced specific worldview beliefs (AAAS 1989, pp. 63-68, 112-113, 118-119, 1990, p. 24). Manifestly, the action in these examples is in the evidence, or even in multiple lines of evidence converging on the same answer, rather than in presuppositions. So, this worldview import derives from empirical, public, scientific evidence.

Finally, where is it reasonable to expect worldview inquiries using empirical and public evidence to be located? As already documented and argued here, science's worldview implications constitute a proper and vigorous topic in science, philosophy, and education. Nevertheless, the next section explains that the primary location for empirical worldview inquiries may be expected elsewhere, in natural theology.

\section{The Testability of Worldviews}

That science deals with testable matters involving empirical and publicly accessible evidence, whereas worldviews or religions deal with untestable matters, is a popular perception. In common parlance, science has facts, whereas religion has faith. Admittedly, both friends and foes of religion express this outlook (for example, Collins 2006; Dawkins 2003). But does this make sense? The answer to this question involves not only natural science, but also natural theology.

The article on "natural theology" by Scott MacDonald in the Routledge Encyclopedia of Philosophy begins with "Natural theology aims at establishing truths or acquiring knowledge about God (or divine matters generally) using only our natural cognitive resources," as contrasted with revealed theology (Craig 1998, vol. 6, pp. 707-713; likewise, see Audi 1999, p. 911; Blackburn 2005, p. 247). He further explains that "The phrase 'our natural cognitive resources' identifies both the methods and data for natural theology: it relies on standard techniques of reasoning and facts or truths in principle available to all human beings just in virtue of their possessing reason and sense perception."

Natural theology considers arguments both for and against theism, with proponents of both sides sharing a common impartial methodology. Because natural theology relies on empirical and public evidence to test competing hypotheses, which is the essence of scientific method, natural theology is that discipline within theology conducted by scientific method. Accordingly, natural theology honors the AAAS's energetic call, already reviewed in Section 3, for scientific method to be applied in diverse domains of thought and life beyond science itself. 
Hence, one possibility is that evidence for worldview issues - such as whether God exists and whether the universe is purposeful - that is found in the natural world would primarily be assigned to natural theology, rather than natural science. Clearly, that territorial choice leaves unchanged the real issue of the strength of that evidence. It also leaves unchanged the character of that evidence. Natural science and natural theology alike rely on reasoning and facts available to all human beings with their endowments of reason and sense perception, that is, they both rely on empirical and public evidence (Gauch et al. 2002). Natural science seeks empirical evidence that bears on scientific hypotheses, whereas natural theology seeks empirical evidence that bears on worldview hypotheses. The relationship between natural science and natural theology is not one of complete separation and reciprocal irrelevance, but rather is one of partial overlap, mutual modification, and ongoing complementarity in the exciting pursuit of a unity of knowledge. Rationality can be pursued in both science and religion (Trigg 1993, 1998, 2002).

It is beyond this article's ambitions to argue that natural theology's results support either theism or else atheism, nor alternatively that its indecisiveness favors agnosticism. The defense of any of these three positions would require careful examination of several principal categories of evidence and several key arguments. That labor, however promising or unpromising it might be, would be considerable.

However, this is the place to argue that the sheer existence and character of this academic discipline invalidates any breezy dismissal of the idea that worldviews are testable. Three common dismissals all fail.

First, breezy dismissal cannot be effected by presuppositions. Some scientists, philosophers, and educators advocate that science must necessarily presuppose that supernatural beings do not exist, or at least that supernatural beings do not interact with physical things in observable ways (as will be discussed more in Section 8). This is a breezy move because presuppositions are just adopted; they are neither questioned nor defended. But recall from Section 5.2 that science's legitimate presuppositions include no such worldview-distinctive content. More fundamentally, human presuppositions have no power to dictate or control reality.

Second, breezy dismissal cannot be effected by stipulations. Many scholars and certainly most scientists exclude supernatural entities from scientific explanations. But again, even if this methodological naturalism is adopted for science in a whole-hearted and even breezy manner, this move is irrelevant for present concerns. This section concerns whether empirical and public evidence can bear on worldview hypotheses within an inquiry having worldview-independent presuppositions. That does not depend on whether such evidence is in the domain of science or other disciplines or 
both. Recall from Section 3 that the substantive question concerns what "the sciences and humanities" combined can do with empirical evidence, which Thesis 3 reiterates as "empirical evidence in general," in contrast to just scientific evidence.

Third, breezy dismissal cannot be effected by in-principle arguments. An in-principle argument shows that by the very meanings of terms, or by the immediate implications of logical or methodological principles, that some particular outcome obtains - so no arduous, detailed empirical investigation is needed to reach a verdict.

The most famous example of an in-principle argument bearing on worldview testability is Hume's enormously influential argument against miracles (David Hume, in Earman 2000, pp. 140-157). He argued that the testimony for reported miracles (including those in the Bible), which is often presented as evidence in favor of a theistic worldview, cannot possibly overturn these miracles' antecedent improbability based on the observed uniform course of nature. As Earman (2000, p. 5) observed, Hume's novelty was "to launch an in-principle attack on the possibility of establishing the credibility of religious miracles." The immediate implication is that no detailed examination of historical or other empirical evidence is necessary or even helpful for reaching a verdict on miracles, quite contrary to the tenor of the preceding literature on miracles. The appeal of in-principle verdicts, when appropriate, is that they can require less work and yet be more conclusive and comprehensive than empirical studies.

But Earman delivered a magisterial case that Hume's attack on miracles fails. In essence, Hume's understanding of probability theory is simplistic and his consideration of multiple witnesses is inadequate. Hume's argument has fallen on exceedingly hard times indeed (Houston 1994; Holder 1998; Shogenji 2003).

The bottom line is simple and compelling for this and other in-principle arguments that attempt to make claims about reality: To know what happens in our world, you cannot just sit in your armchair and philosophize, but rather you must go and look and see what happens.

The conclusion that natural theology merits careful examination, not breezy dismissal, has three implications for science education. First and foremost, a verdict on worldview testability requires a wider survey than just natural science. The key claim in the popular perception mentioned at the outset of this section is: Worldview hypotheses are untestable with empirical and public evidence. But understand that this requires the supporting claim: Natural theology is a complete failure. Therefore, only after someone has proven natural theology to be an abject failure is he or she in a position to argue that worldviews are untestable - and also has overturned the mainstream position that science itself has empirical and public 
evidence contributing to a meaningful worldview. By their very nature, worldview hypotheses are testable if they predict different outcomes for physical and publicly observable events - that is, if they exemplify successful exercises in natural theology or other empirical disciplines.

Second, because worldview testability involves arduous examination of many kinds of empirical evidence, both inside and outside the natural sciences, this topic is unsuitable as a requirement for scientific literacy. On the other hand, because mainstream science (as represented by AAAS position papers) commends the application of scientific thinking in diverse domains of inquiry and life, the bearing of empirical evidence on worldview hypotheses is a legitimate interest of individual scientists, philosophers, educators, historians, and others.

Third and finally, scientism is objectionable. To believe that only science has testable, real knowledge - not philosophy or theology or any other discipline - is simply unmitigated scientism. Hansson and Redfors (2006b) identified three interrelated aspects of scientism that are common in students' perceptions of science: "Everything has or will have a scientific explanation," "Things that cannot be proven or explained [by science] do not exist," and "One should not believe in things that are not proven [by science]." They emphasized that science educators should help students to avoid these misconceptions. Clearly, scientism is an affront to pillar P5 regarding science's limits. Scientism is outside mainstream science, as delineated consistently by position papers on science education. For instance, "Students should develop an understanding of what science is, what science is not, what science can and cannot do, and how science contributes to culture" (NRC 1996, p. 21). Science contributes to culture by energetically proclaiming its own testable knowledge - not by denouncing additional sources of testable knowledge that may in fact have great legitimacy and value.

The previous Section 5.3 defended the mainstream position that scientific evidence can have worldview import. The thrust of this section has been that the broader resources of the sciences and the humanities combined have more potential for worldview import than the limited resources of the sciences alone. In the humanities, the sciences have allies in the pursuit of realism and meaning.

\section{Three Problematic Perspectives}

Section 5 explored the implications of science's method for science's potential to weigh worldview hypotheses. By contrast, this section examines three prominent examples of alternative perspectives and shows them to be problematic. 
The first two examples selected here are the two statements about science's worldview import that were quoted earlier from AAAS position papers on science. So far, it was noted that these two statements are flatly contradictory. But the mere detection of this contradiction says nothing at all about the truth or other merits of either statement - except that they cannot both be true. Hence, further discussion is warranted, particularly in terms of the seven pillars of science that are taken here as beneficial, venerable, stable, nonnegotiable features of mainstream science.

Recall the first statement about science's reach, that there are "beliefs that - by their very nature - cannot be proved or disproved (such as the existence of supernatural powers and beings, or the true purposes of life)." This statement claims that typical worldview issues, such as God's existence and life's purpose, are outside science's purview. On two counts, this claim is problematic.

First, as already documented, major general science journals, and even AAAS position papers, carry a long-standing and ongoing exploration of science's worldview import. So, it is just plain false to say that the scientific community is not engaging worldview interests - even though there is still greater activity, of course, in the philosophical and theological communities. Furthermore, analysis of scientific method shows that in principle, because worldview-distinctive presuppositions are avoided, empirical and public evidence can address worldview hypotheses. Hence, there is neither conventional (stipulatory) nor methodological (substantive) support for this first AAAS claim. When pillar $P 7$ stands, saying that science can contribute to a meaningful worldview, this claim of worldview irrelevance falls.

Second, this AAAS claim is offered dogmatically, without any argumentation or evidence whatsoever. That violates pillar $P 3$, which requires evidence for scientific assertions. That also displays a peculiar disregard for the AAAS's own energetic repudiation of dogmatism and indoctrination (AAAS 1989, p. 135, 1990, p. xi).

Next recall the second AAAS statement, with its insistent preamble that "There can be no understanding of science without understanding," followed by its worldview content about "change and the fact that we live in a directional, although not teleological, universe." This is also a problematic claim.

First, just like the other AAAS claim, this one is also offered dogmatically, without a shred of evidence or argumentation. Yet whether the universe is purposeless or purposeful is highly controversial among scientists, among philosophers, among educators, among people in general, and between worldviews. 
Second, this preamble voices a disturbing rhetoric of exclusion. It excludes all Jews, Christians, Muslims, and others who believe in a purposeful universe from being accepted as persons having an understanding of science. To marginalize a sizable portion of the world's population from being respected participants in science is a flagrant affront to pillar P6 about universality. This preamble also voices a deplorable rhetoric of indoctrination: only one worldview perspective is to be countenanced among the scientifically literate.

Ironically, the two AAAS claims about science's worldview import represent two opposite extremes: that science has nothing to say about typical worldview issues, or that science does support one particular worldview that merits official endorsement by scientific institutions and that compels assent from all scientists and everyone else claiming an understanding of science. By contrast, a mainstream position, which aligns with the seven pillars of science, involves a delicate balance located between these extremes.

On the one hand, mainstream science happily recognizes science's potential, alongside the humanities, to contribute to a meaningful worldview. Hence it is legitimate and exciting for individual scientists to take an interest in science's worldview import and to reach their conclusions. But on the other hand, an institutional mandate for all scientists to reach the same conclusion, say about the universe's purposelessness, seems ill advised. A more flexible and restrained outlook would be that interest in science's worldview import is a valid option for scientists, but not a universal requirement for scientific literacy, and that worldview conclusions are for individual convictions and public discussions but not for institutional endorsements. The possibility must also be borne in mind that for many persons, the humanities, rather than the sciences, may be most informative in their worldview inquiries. Indeed, some individuals may reach their worldview convictions mostly on other grounds, even including personal experiences, and hence find science's role limited to confirming and reinforcing convictions already held.

AAAS position papers are carefully crafted by hundreds of outstanding contributors who work through several drafts over a period of several years with additional input from numerous reviewers. Make no mistake. AAAS position papers are intended to influence actions on the part of the President of the United States, the U.S. secretary of education, both houses of Congress, governors of all states, sources of financial support for science, universities and the agencies that grant them accreditation, business and labor leaders, the news media, military officers, scientists, educators, and finally, the general public (AAAS 1989, pp. 162-167, 1990, pp. 3-6). With great influence comes great responsibility. As they serve the 
scientific community and the larger world, the authors of position papers must clearly discern the different prerogatives and complementary roles of institutions and individuals. By publishing both position papers and $\mathrm{Sci}$ ence, the AAAS provides ideal outlets for both institutional standards and individual opinions.

However regrettable these two AAAS claims about science's worldview import may be, fortunately the AAAS has already expressed humility and openness, saying that "their conclusions are set in a historical context and that all the issues addressed will and should continue to be debated" (AAAS 1990, pp. 25-26). Occasional errors in the course of exciting and real leadership are understandable. Nevertheless, as the AAAS frames its future position papers on science, failure to acknowledge serious errors in previous position papers would be irresponsible. Corrections should be explicit and decisive.

For a third and final example of problematic perspectives on science's worldview import, consider the skepticism about science expressed by $\mathrm{Sir}$ Karl Popper. He and Thomas Kuhn are particularly important scholars in the sense that they, and no other philosophers of science, are well known among scientists. Although many of their ideas are insightful and salutary, there are also some disturbing claims. Scientific American has published interesting interviews with them (Horgan 1991, 1992).

Astonishingly, Popper claimed that "The statement, 'Here is a glass of water' cannot be verified by any observational experience" because of philosophical problems regarding universals that grip everyone (Popper 1968 , p. 95). Now to say that "Here is a glass of water" is a knowledge claim beyond human competence constitutes a plainly spoken denial of common sense, just as would be rejection of the previous exemplars of rudimentary knowledge, such as "Moving cars are hazardous to pedestrians." O'Hear (1989, p. 91) and Gauch (2002, pp. 136-137, 148) find such skepticism unwarranted and disturbing. If the trivial common-sense observation, "Here is a glass of water," is beyond humans, then the harder scientific finding, "Water is composed of hydrogen and oxygen," is way beyond us and challenging worldview conclusions are way, way beyond us. Such a crippled science has no worldview import. (Incidentally, Popper's careful readers will have noticed the subtle irony here, that his readership is humans, even though humans constitute a universal just like glasses of water. Popper is entitled to speak for himself and to report that he has trouble with universals, but on his own terms, he cannot help himself to the presumption that other humans also suffer this same affliction.)

Likewise, Kuhn's claim that science is "arational," expressed "with no trace of a smile" in his interview for Scientific American, is outside mainstream science that affirms science's logic (pillar P4). Another philosopher 
of science, Paul Feyerabend, has expressed an even more skeptical view of science (Broad 1979; Theocharis and Psimopoulos 1987; Horgan 1993). Various skeptical, relativistic, and postmodern assessments of science collectively have considerable currency (Koertge 1998).

But mainstream science rejects radical skepticism and universal fallibilism, not with evidence, but with the presupposition that the world is orderly and comprehensible (pillar P2). Again, whatever philosophy's interests and business may be, science's project is to presuppose common sense and then build scientific method, not to refute the skeptic and thereby establish common sense.

Incidentally, Popper and Kuhn have had unmistakable influence on the two AAAS position papers discussed here, although they are not named or cited. The ideas of underdetermined theories and paradigm shifts appear repeatedly (AAAS 1989, pp. 26-27, 1990, pp. 17-18, 21, 24). Their skeptical tendencies play out in an awkward tension between science being "tentative" and "revisable," and yet also being "durable" despite drastically diminished claims of being "true" (AAAS 1989, p. 26, 1990, pp. 20-21). The same ambivalence pervades position papers on science education from many nations (McComas 1998).

However, deeming durability to be good presumes that durability is serving as a truth surrogate since the persistence of a false idea is bad. A historical or sociological claim of durability just cannot do the job of a scientific or philosophical claim of truth. Also, this attempted distancing from truth claims, presumably in the cause of philosophical sophistication, is inevitably facile and disappointingly sophomoric because these position papers confidently present literally hundreds of indisputable scientific facts that are anything but tentative and revisable. Plainly, some scientific ideas are certain, some are probable, and some are quite speculative. So, it is misleading to say that "Scientific knowledge," without any qualification, "is tentative, approximate, and subject to revision" (AAAS 1990, p. 20).

Kuhn (1970) and his interview in Scientific American (Horgan 1991) are cited in a report to Congress, The Objectivity Crisis: Rethinking the Role of Science in Society (Brown 1993). The Congress of the United States wanted a current assessment of science's rationality and objectivity, so a 1993 symposium was co-convened by Representative George Brown and the AAAS for the purpose of providing "a philosophical backdrop for carrying out our responsibilities as policymakers" (p. iii). One contributor, influenced by Kuhn, reported that scientists should accept the new picture of science as myth. "Some scientists are still scandalized by the historical insight that science is not a process of discovering an objective mirror of nature, but of elaborating subjective paradigms subject to empirical constraints. ... Nevertheless, it is important to understand the nature, function, 
and necessity of scientific paradigms and other myths. ... [We] must depend on a priori faith in our various myths and sub-myths to exploit our limited capacity for reason" (Ronald D. Brunner, in Brown 1993, p. 6). Needless to say, some scholars might prefer that policymakers receive a less skeptical and more balanced view of science's powers and limits.

My reason for selecting these particular examples is their occurrence in influential position papers, but equally is their wide currency in popular conceptions of science. One need not look very long to find expressions of these three common views. (1) Careful science should be silent about worldview questions because science and religion are separate, nonoverlapping magisteria. (2) Modern science should unhesitatingly get on with a thoroughly naturalistic, atheistic worldview. (3) Postmodern science should forego universal truth claims about anything, especially worldviews. By contrast, I hold a fourth position. (4) The sciences and humanities can consider informative evidence that supports specific worldview conclusions suitable for individual convictions and public discussions but not institutional endorsements.

\section{Necessary and Unnecessary Presuppositions}

The most extensive discussion in this journal of the present topic - science, worldviews, and education - is in the special issue on "Religion and Science Education," edited by Matthews (1996). That issue provided an admirably fair and open forum for proponents of contrasting worldviews to present their positions. It begins with an article by Mahner and Bunge (1996a) followed by six responses (Lacey 1996; Poole 1996; Settle 1996; Turner 1996; Woolnough 1996; Wren-Lewis 1996) and finally a reply by Mahner and Bunge (1996b). The lead article defends two theses: that "a religious education is detrimental to a scientific one" and that "science and religion are incompatible." The six responses, which include diverse theistic perspectives, critique Mahner and Bunge on many counts. But in their final reply, Mahner and Bunge claim that "these criticisms fail to affect our position."

The chief feature of this extended exchange is its lack of progress - its lack of effective engagement. Those who see science and religion as being compatible and those who see them as being incompatible are talking past each other - as any and every observer of this exchange can immediately see. Why? Why this lack of engagement, this lack of progress, this lack of change in view?

Well, there are obvious sociological and psychological factors. People are raised with different cultures or religions or worldviews, and by their very nature of addressing life's biggest issues, worldviews are often held in 
a rather entrenched manner. Nevertheless, moving on to intellectual factors, confusion about science's presuppositions is playing a huge role in this exchange. Accordingly, the salutary call from Hansson and Redfors (2006b) to distinguish between science's necessary and unnecessary presuppositions is pursued in this section.

Mahner and Bunge (1996a) repeatedly insist that science must presuppose materialism. (Incidentally, despite some fine distinctions, they and their responders use "materialism" and "naturalism" and "atheism" as virtual synonyms.) However, explication of what they mean by a presupposition awaits their reply, Mahner and Bunge (1996b). "When we say that science presupposes materialism we mean something far stronger than just 'science entails materialism'. That is, we mean that science would be rendered impossible if scientists were to take any ontological assumption above and beyond naturalism seriously." Furthermore, they reply to one of their responders, saying: "Lacey appears to say that what we call a "presupposition' of science, whether ontological, epistemological, or moral, is equivalent to faith in religion. However, nobody can argue in a vacuum, that is, without a basis of assumptions or presuppositions that are not questioned in the given context. In particular, nobody can do without a general outlook or world view."

At this point, it is instructive to turn to the Cambridge and Oxford dictionaries of philosophy for a definitive definition of this pivotal term, presupposition (Rod Bertolet, in Audi 1999, p. 735; Blackburn 2005, p. 290). Two notions are specified. The informal or pragmatic notion of presupposition is a belief that a speaker takes for granted, which though it is implicit and undefended, contributes to making the speaker's position tenable. On the other hand, the formal or semantic notion is a belief that is a precondition for another proposition to be either true or false. The archetypical exemplar is that in order for the proposition, "The present king of France is bald," to be either true or false, the presupposition that "The present king of France exists" must hold. Otherwise, that proposition simply lacks a referent, and so it is neither true nor false. A special kind of semantic presuppositions is termed absolute presuppositions. All propositions capable of truth or falsity within a system of thought depend ultimately on absolute presuppositions so deep that this system cannot possibly even question them. For instance, all intellectual life that takes place in community - such as the scientific community - presupposes that humans can communicate with one another, at least to some usable degree. Any contrary view is best regarded as a joke. The contrary is like the solipsist who asked a philosopher whether her own self is all that exists, whereupon the philosopher replied, "Why did you write a letter to me?" Again, it is like the Burns and Allen routine where Gracie tells an 
incredulous George about a boy who, in order to avoid having to purchase a train ticket, talked the conductor into believing that he was too young to speak. To talk about whether we can talk is nothing but an exercise in insincerity - unless it is a joke.

Given this clear terminology - pragmatic, semantic, and absolute presuppositions - exactly what do Mahner and Bunge have in mind? The first quotation, about science being rendered impossible apart from presupposing materialism, clearly implicates a semantic presupposition. And the second quotation, about science needing an unquestioned basis or worldview because nobody can argue in a vacuum, seems like the language of an absolute presupposition, though the coarser identification as a semantic presupposition suffices here.

But does their presupposition of atheism pass muster? On three counts, it does not.

First, whether or not scientific thinking requires an atheistic worldview just is the grand debate in this exchange. So, although Mahner and Bunge may themselves regard this as a high-grade semantic presupposition, as this presupposition travels into the wider world of public discourse that also involves other persons, it must function as a mere pragmatic presupposition. Unless their audience happens to share the authors' presupposition, it lacks force in other persons' thinking. Needless to say, a pragmatic presupposition is problematic if the speaker's audience has many individuals who do not also take the speaker's presupposition for granted.

Second, this presupposition, that science is rendered impossible without naturalism, essentially equals their theses merely expressed in different words, namely that science and religion are incompatible and hence religion is detrimental to science. So, Mahner and Bunge presuppose the truth of their theses. That is the very last thing that should ever be done with a thesis, to presuppose it! Recall the inexorable logic that that which is presupposed cannot also be concluded. Also recall that by definition, a presupposition is an unquestioned, undefended proposition. Hence, to proclaim naturalism as a presupposition, without evidence, rather than as a conclusion, with evidence, is to offer it in the weakest possible manner. When presuppositions dominate the outcome of a discussion or debate, that precludes evidence from having its proper influence.

Third and finally, Mahner and Bunge's papers exhibit a tortuous ambiguity between presuppositions and conclusions. They could hardly be more concise and insistent when they say, "science presupposes materialism" (italics theirs). And yet, throughout their papers, line after line of argumentation and evidence say that science supports or concludes materialism. They seem to want their materialism as both a presupposition and a conclusion of science - but of course, they cannot have it both ways. 
A presupposition can be disclosed, or even can be legitimated relative to a specified audience, but it cannot be vigorously defended by arguments and evidence and still retain its logical role or status as a presupposition.

Most forcefully, they take their claim that science explains everything, along with some help from Ockham's razor, as strong and even compelling evidence in favor of materialism. However, this argument that science explains everything merely shifts the action to the question: What is this "everything" that science explains? For instance, to recall a repeated dispute among the authors in that special issue, was Christ resurrected after being dead for three days and does this reported miracle have strong historical evidence? Accordingly, does this "everything" that has happened in our world include or exclude Christ's resurrection?

Because of the debate over Christ's resurrection, which is but one among a thousand other disputed matters, there simply is no settled, public version of the "everything" that either science or a more comprehensive approach is burdened to explain. Consequently, the argument that science can explain everything - let alone the further contention that this success supports or necessitates naturalism - is a nonstarter, destined to perish amidst a thousand controversies without public consensus. Certainly, a scientist may claim that science can or will explain everything that he or she judges to be factual, but this appropriately weakened claim is too personal and subjective to interest the wider world.

The exchange reviewed in this section, which was published a decade ago, still reverberates in its journal's pages. Just several of the subsequent papers that have cited papers in that exchange are Martin (1997), Cobern (2000), Southerland (2000), and Gauld (2005). The presumption of materialism remains a common perspective. For instance, in Scientific American, Johnson (2006) opines, "The assumption of materialism is fundamental to science."

As the discussion of science, worldviews, and education continues, presuppositions will be enormously influential. Necessary presuppositions enable science to have a mainstream, realist interpretation. Unnecessary presuppositions of science can hinder discussions of important issues from progressing, erode the proper influence of evidence, blur the distinction between presuppositions and conclusions, undermine science's status as a public endeavor, and pick needless fights regarding religions and worldviews.

\section{Conclusions}

Science's method is the main determinant of its potential for reaching conclusions with substantial worldview import. Perforce, such conclusions are 
based on publicly accessible evidence, standard reasoning, and minimal, common-sense, worldview-independent presuppositions. Precisely because science does not presuppose worldview-distinctive beliefs, such beliefs retain eligibility to become conclusions of science if admissible and relevant evidence is available. Indeed, the mainstream view is that the sciences and humanities can contribute to a meaningful worldview. Worldview-distinctive conclusions based on empirical evidence are suitable for individual convictions and public discussions, but not for institutional endorsements and scientific literacy requirements.

Across the nations and over the centuries, diverse views of science's worldview import have been fashionable. Consequently, current fashions are not a reliable indicator of scientific orthodoxy. Instead, the test of orthodoxy commended here is coherence with science's most basic commitments, particularly the seven pillars that have been stable features of science for centuries and are also affirmed by the AAAS. Those strong pillars and their clear implications are great ideas that can be expected to endure, across the nations and over the centuries.

\section{References}

AAAS (American Association for the Advancement of Science): 1989, Science for All Americans, AAAS, Washington, DC.

AAAS: 1990, The Liberal Art of Science, AAAS, Washington, DC.

Anscombe, G.E.M. \& Wright, G.H.: 1969, Ludwig Wittgenstein's on Certainty, Harper \& Row, New York.

Audi, R. (eds.): 1999, The Cambridge Dictionary of Philosophy 2nd edn, Cambridge University Press, Cambridge.

Bering, J.M.: 2006, 'The Cognitive Psychology of Belief in the Supernatural', American Scientist 94, 142-149.

Blackburn, S. (eds.): 2005, The Oxford Dictionary of Philosophy 2nd edn, Oxford University Press, Oxford.

Broad, W.J.: 1979, 'Paul Feyerabend: Science and the Anarchist', Science 206, 534-537.

Brown, G.E.: 1993, The Objectivity Crisis: Rethinking the Role of Science in Society, Chairman's report to the Committee on Science, Space, and Technology, House of Representatives, 103rd Congress, first session, serial D, U.S. Government Printing Office, Washington, DC.

Callender, C.: 2004, 'Measures, Explanations and the Past: Should "Special" Initial Conditions be Explained?', British Journal for the Philosophy of Science 55, 195-217.

Cobern, W.W.: 2000, 'The Nature of Science and the Role of Knowledge and Belief', Science \& Education 9, 219-246.

Cobern, W.W. \& Loving, C.C.: 2001, 'Defining "Science" in a Multicultural World: Implications for Science Education', Science \& Education 85, 50-67.

Collins, F.S.: 2006, The Language of God: A Scientist Presents Evidence for Belief, Free Press, New York.

Conway Morris, S.: 2003, Life's Solution: Inevitable Humans in a Lonely Universe, Cambridge University Press, Cambridge.

Craig, E. (eds.): 1998, Routledge Encyclopedia of Philosophy, Routledge, New York. 
Craig, W.L.: 1992, 'The Origin and Creation of the Universe: A Reply to Adolf Grünbaum', British Journal for the Philosophy of Science 43, 233-240.

Davson-Galle, P.: 2006, 'Why Compulsory Science Education Should Not Include Philosophy of Science', Science \& Education 15, (in press).

Dawkins, R.: 2003, A Devil's Chaplain: Reflections on Hope, Lies, Science, and Love, Houghton Mifflin, Boston.

Dennett, D.C.: 2006, Breaking the Spell: Religion as a Natural Phenomenon, Viking, New York.

Earman, J.: 2000, Hume's Abject Failure: The Argument Against Miracles, Oxford University Press, Oxford.

Easterbrook, G.: 1997, 'Science and God: A Warming Trend?', Science 277, 890-893.

Gauch, H.G.: 2002, Scientific Method in Practice, Cambridge University Press, Cambridge; Chinese edition 2004, Tsinghua University Press, Beijing.

Gauch, H.G.: 2006, 'Winning the Accuracy Game', American Scientist 94, 133-141; correspondence 2006, 94, 196; addendum 2006, 94, 382.

Gauch, H.G., Bloom, J.A. \& Newman, R.C.: 2002, 'Public Theology and Scientific Method: Formulating Reasons That Count Across Worldviews', Philosophia Christi 4, 45-88.

Gauld, C.F.: 2005, 'Habits of Mind, Scholarship and Decision Making in Science and Religion', Science \& Education 14, 291-308.

Gruender, D.: 2001, 'A New Principle of Demarcation: A Modest Proposal for Science and Science Education', Science \& Education 10, 85-95.

Grünbaum, A.: 2000, 'A New Critique of Theological Interpretations of Physical Cosmology', British Journal for the Philosophy of Science 55, 1-43.

Grünbaum, A.: 2004, 'The Poverty of Theistic Cosmology', British Journal for the Philosophy of Science 55, 561-614.

Grünbaum, A.: 2005, 'Rejoinder to Richard Swinburne's "Second Reply to Grünbaum"”, British Journal for the Philosophy of Science 56, 927-938.

Hansson, L. \& Redfors, A.: 2006a, 'Physics and the Possibility of a Religious View of the Universe: Swedish Upper Secondary Students' Views', Science \& Education 15, (in press).

Hansson, L. \& Redfors, A.: 2006b, 'Upper Secondary Students in Group Discussions About Physics and our Presuppositions of the World', Science \& Education, 15, (in press).

Hofmann, J.R. \& Weber, B.H.: 2003, 'The Fact of Evolution: Implications for Science Education', Science \& Education 12, 729-760.

Holder, R.D.: 1998, 'Hume on Miracles: Bayesian Interpretation, Multiple Testimony, and the Existence of God', British Journal for the Philosophy of Science 49, 49-65.

Horgan, J.: 1991, 'Profile: Thomas S. Kuhn, Reluctant Revolutionary', Scientific American 264(5), 40, 49.

Horgan, J.: 1992, 'Profile: Karl R. Popper, The Intellectual Warrior', Scientific American 267(5), 38-44.

Horgan, J.: 1993, 'Profile: Paul Karl Feyerabend, The Worst Enemy of Science', Scientific American 268(5), 36-37.

Horgan, J.: 2005, 'Clash in Cambridge: Science and Religion Seem as Antagonistic as Ever', Scientific American 293(3), 24B-28.

Houston, J.: 1994, Reported Miracles: A Critique of Hume, Cambridge University Press, Cambridge.

Irzik, G. \& Irzik, S.: 2002, 'Which Multiculturalism?', Science \& Education 11, 393-403.

Johnson, G.: 2006, 'Scientists on Religion: Theist and Materialist Ponder the Place of Humanity in the Universe', Scientific American 295(4), 94-95. 
Keeports, D. \& Morier, D.: 1994, 'Teaching the Scientific Method: Assessing a Seminar on Science and Pseudoscience at Oakland's Mills College', Journal of College Science Teaching 24, 45-50.

Keranto, T.: 2001, 'The Perceived Credibility of Scientific Claims, Paranormal Phenomena, and Miracles among Primary Teacher Students: A Comparative Study', Science \& Education 10, 493-511.

Koertge, N. (eds.): 1998, A House Built on Sand: Exposing Postmodernist Myths about Science, Oxford University Press, Oxford.

Kuhn, T.S.: 1970, The Structure of Scientific Revolutions 2nd edn, University of Chicago Press, Chicago.

Lacey, H.: 1996, 'On Relations between Science and Religion', Science \& Education 5, $143-153$.

Larson, E.J. \& Witham, L.: 1999, 'Scientists and Religion in America', Scientific American 281(3), 88-93.

Lindberg, D.C. \& Numbers, R.L. (eds): 2003, When Science \& Christianity Meet, University of Chicago Press, Chicago.

Machamer, P: 1998, 'Philosophy of Science: An Overview for Educators', Science \& Education $7,1-11$.

Mahner, M. \& Bunge, M: 1996a, 'Is Religious Education Compatible with Science Education?', Science \& Education 5, 101-123.

Mahner, M. \& Bunge, M.: 1996b, 'The Incompatibility of Science and Religion Sustained: A Reply to Our Critics', Science \& Education 5, 189-199.

Martin, M: 1997, 'Is Christian Education Compatible with Science Education?', Science \& Education 6, 239-249.

Matthews, M.R.: 1994, Science Teaching: The Role of History and Philosophy of Science, Routledge, New York.

Matthews, M.R.: 1996, 'Editorial', Science \& Education 5, 91-99.

Matthews, M.R.: 2000, Time for Science Education: How Teaching the History and Philosophy of Pendulum Motion can Contribute to Science Literacy, Kluwer Academic, New York.

Matthews, M.R.: 2004, 'Review of Scientific Method in Practice by Hugh G. Gauch, Jr.', Science \& Education 13, 251-252.

McComas, W.F. (eds.): 1998, The Nature of Science in Science Education: Rationales and Strategies, Kluwer, New York.

Monton, B.: 2006, 'God, Fine-Tuning, and the Problem of Old Evidence', British Journal for the Philosophy of Science 57, 405-424.

Nash, L.K.: 1963, The Nature of the Natural Sciences, Little Brown and Company, Boston.

Nola, R.: 2003, 'Naked before Reality; Skinless before the Absolute: A Critique of the Inaccessibility of Reality Argument in Constructivism', Science \& Education 12, 131-166.

NRC (National Research Council): 1996, National Science Education Standards, National Academy Press, Washington, DC.

NRC: 1999, Transforming Undergraduate Education in Science, Mathematics, Engineering, and Technology, National Academy Press, Washington, DC.

O'Hear, A.: 1989, An Introduction to the Philosophy of Science, Oxford University Press, Oxford.

O'Hear, A.: 1993, 'Science and Religion', British Journal for the Philosophy of Science 44, $505-516$.

Palmer, H.: 1985, Presupposition and Transcendental Inference, St. Martin's Press, New York.

Pennock, R.T.: 2002, 'Should Creationism be Taught in the Public Schools?', Science \& Education 11, 111-133.

Polanyi, M.: 1962, Personal Knowledge, University of Chicago Press, Chicago. 
Poole, M.: 1996, '... For More and Better Religious Education', Science \& Education 5, $165-174$.

Popper, K.R.: 1968, The Logic of Scientific Discovery, Harper \& Row, New York.

Schupbach, J.N.: 2005, 'On a Bayesian Analysis of the Virtue of Unification', Philosophy of Science 72, 594-607.

Settle, T.: 1996, 'Applying Scientific Openmindedness to Religion and Science Education', Science \& Education 5, 125-141.

Sherburn, R.: 2004, 'Review of Scientific Method in Practice by Hugh G. Gauch, Jr.', Journal of Biological Education 38(2), 98.

Shogenji, T.: 2003, 'A Condition for Transitivity in Probabilistic Support', British Journal for the Philosophy of Science 54, 613-616.

Smith, M.U., Siegel, H. \& McInerney, J.D.: 1995, 'Foundational Issues in Evolution Education', Science \& Education 4, 23-46.

Southerland, S.A.: 2000, 'Epistemic Universalism and the Shortcomings of Curricular Multicultural Science Education', Science \& Education 9, 289-307.

Sterelny, K.: 2006, 'Memes Revisited', British Journal for the Philosophy of Science 57, $145-165$.

Swinburne, R.: 2000, 'Reply to Grünbaum', British Journal for the Philosophy of Science 51, $481-485$.

Swinburne, R.: 2005, 'Second Reply to Grünbaum', British Journal for the Philosophy of Science 56, 919-925.

Theocharis, T. \& Psimopoulos, M.: 1987, 'Where Science has Gone Wrong', Nature 329, 595-598; correspondence 1987, 330, 308, 689-690, 1988, 331, 129-130, 204, 384, 558; reply $1988, \mathbf{3 3 3}, 389$.

Trigg, R.: 1993, Rationality and Science: Can Science Explain Everything?, Blackwell, Oxford.

Trigg, R.: 1998, Rationality and Religion: Does Faith Need Reason?, Blackwell, Oxford.

Trigg, R.: 2002, Philosophy Matters: An Introduction to Philosophy, Blackwell, Oxford.

Turner, H.: 1996, 'Religion: Impediment or Savior of Science?', Science \& Education 5, $155-164$.

Weisberg, J.: 2005, 'Firing Squads and Fine-Tuning: Sober on the Design Argument', British Journal for the Philosophy of Science 56, 809-821.

Woolnough, B.E.: 1996, 'On the Fruitful Compatibility of Religious Education and Science', Science \& Education 5, 175-183.

Wren-Lewis, J.: 1996, 'On Babies and Bathwater: A Non-Ideological Alternative to the Mahner/Bunge Proposals for Relating Science and Religion in Education', Science \& Education 5, 185-188. 